\title{
COVID-19 e medo Social: vivências emocionais em tempos de pandemia
}

COVID-19 and Social Fear: emotional experiences in pandemic times

Marilene Salgueiro ${ }^{1}$ Universidade Federal da Paraíba msalgueiro6@gmail.com doi: $x x x x x x x x x x x$

\begin{tabular}{|c|c|c|}
\hline Recebido / Received & Aceite / Accepted & Publicado / Published \\
18.07 .2020 & 1.1 .2020 & 1.06 .2021 \\
\hline
\end{tabular}

Como citar este capítulo / How to quote this chapter:

Salgueiro, M. (2021). "COVID-19 e medo social: vivências emocionais em tempos de pandemia". In Reis, B., Um mundo de incertezas; as leituras possiveis de um tempo pandémico (pp. 95-111). Lisboa: NIP-C@M \& UAL, disponível em $\underline{x x x x x x x x x}$. DOI xxxxxxx. 


\section{Introdução}

No contexto da atual situação vivenciada pela população mundial oriunda da pandemia de COVID-19 e das suas consequências, este capítulo objetiva apresentar uma reflexão sobre a vivência emocional e a emoção do medo, analisando as interfaces entre o medo enquanto emoção natural e enquanto construção social. O coronavírus (COVID-19), surgiu na China no final do ano de 2019 e após atingir outros países originou, segundo a Organização Mundial da Saúde (OMS), uma pandemia. O mundo acompanhou atentamente as notícias sobre o novo coronavírus que começou a aparecer como uma ameaça real e cada vez mais próximo de cada pessoa. A realidade imposta pela pandemia, ao alterar o cotidiano, estabeleceu novas rotinas e colocou-nos diante de um perigo que ameaça a vida e que exacerbou as emoções, provocando alterações na saúde física e emocional, causada por esta nova forma de vivenciar as ações diárias. A emoção do medo é sem dúvida a predominante neste contexto, sendo necessário refletir como está sendo vivenciada neste momento histórico.

\section{A emoção do medo: reação natural e construção social}

O medo é uma das emoções básicas e inatas de qualquer ser humano. O medo enquanto emoção inata é manifesta e exerce uma função protetiva. Na evolução das espécies é inegável o

1 Doutora em Educação. Professora Adjunta do Centro de Educação da Universidade Federal da Paraíba, João Pessoa, Brasil. 
papel do medo. Assim, o medo é uma das maiores heranças emocionais da nossa espécie.

Diante do exposto e considerando o contexto atual traremos aqui uma perspetiva de discussão do Medo Social, quando o medo assume algumas caraterísticas nas sociedades, no contexto social no qual nós estamos inseridos enquanto indivíduos, em relação com outros. Nós não vivemos isolados e nem vivemos numa bolha protetora dos problemas que nos ameaçam. Na verdade, estamos em contato direto com tudo que nos cerca, sendo imprescindível que a emoção do medo seja entendida a partir dos seus aspetos e das definições que alcança nas estruturas sociais.

As emoções têm uma função na nossa relação social, ou na nossa vivência em sociedade, servem para comunicar os sentimentos, influenciar a forma como as pessoas interagem e se relacionam, facilitar e possibilitar interações sociais saudáveis, mas também podem criar, manter e acabar com os relacionamentos.

A emoção do Medo sofre influências culturais e sociais, de onde surge uma interação emocional em que a ação de alguém interfere na resposta emocional de outros. A geração de respostas emocionais acontece a partir de Estímulos Emocionais competentes, que Damásio (2004) configura como qualquer evento externo ou interno que nos atinge e provoca uma reação. 
A emoção inata do medo assume caraterísticas distintas ao ser produzida socialmente. O medo social não é apenas uma emoção inata, mas constitui-se na inserção dos sujeitos na sociedade, numa emoção produzida socialmente que se torna difusa e semelhante, a ansiedade. $\mathrm{O}$ medo social surge através de relações de poder desequilibradas, que originam um mecanismo de controlo social pelo qual é gerada uma crise de confiança onde os sujeitos passam a questionar a si mesmos, as suas capacidades e o meio em que se inserem.

O ponto de partida é perceber como esses estímulos emocionais são desenvolvidos nas sociedades para exacerbar ou provocar a emoção do medo. Ao considerarmos que as emoções, dentre elas o medo, também são manifestação e expressão cultural teremos o fato de que dependendo da cultura, do espaço, da região e da sociedade no qual o sujeito está inserido, essa manifestação se dá de forma diferenciada.

Para Bauman (2008), encontramos três formas de expressão do medo: a primeira quando estamos ou imaginamos estar em perigo em relação ao corpo e às propriedades; a segunda relacionada aos perigos difusos que a ordem social gera; inseguranças de confiança nos governos, segurança na sobrevivência através da geração de emprego e renda, e a terceira relacionada com a identidade que possibilita sentir incluídos ou excluídos da sociedade. 


\section{Entre a razão e a emoção: respostas ao COVID-19}

Observa-se que tal cenário oriundo da pandemia é propulsor de diversas ações emergenciais, cujo primeiro impacto é a proteção da vida. Dentre as ações impulsionadas pelas autoridades governamentais e de saúde, o isolamento social, considerado como a mais efetiva forma de enfrentamento do COVID-19 é, sem dúvida, aquela que transformou, fundamentalmente, o cotidiano das pessoas redefinindo as formas de agir, ver e sobretudo sentir.

Repentinamente, fomos todos privados da liberdade, do ir e vir, do trabalho, escolas e eventos sociais, o que causou um afastamento do convívio diário com pessoas próximas e familiares. Com o objetivo de proteger os idosos, o contato entre avós, netos, pais e filhos foi impedido. Ações consideradas como demonstração de amor tais como, afagos, aperto de mãos, abraços e carinhos, de repente se transformaram em perigo.

Nosso Norte foi virado drasticamente. Em enquete recentemente realizada pelo Centro de Investigaciones y Estudios Sociológicos (CIES), sobre os efeitos do COVID-19 na América Latina, citada em artigo de Koury (2020), com 2.475 depoimentos, os sentimentos de tristeza, ansiedade e a emoção do medo predominaram. Desses casos, o Brasil está representado com 707 respondentes, destacando-se as emoções de ansiedade, medo e tristeza que somam quase $90 \%$ das respostas. 
Diante desses fatos, as emoções naturais, a tristeza e o medo, são vivenciados sob um novo espetro mundial. Apesar do fenómeno que emocionalmente interfere na nossa vida, somos levados a racionalizar o contexto. Trava-se, assim, a luta entre razão e emoção que, com as suas similaridades não se opõem, mas serão complementares nos resultados obtidos.

O ser humano, como animal racional, vai além da racionalidade por via da sua complexidade. Somos também seres emocionais, capazes de nos sensibilizarmos com uma paisagem, de nos alegrarmos diante de conquistas e de nos entristecermos ao encarar tragédias e dores. Diante de um perigo imediato somos assaltados pela emoção do medo. As emoções dão o tom das nossas vivências pessoais e sociais.

A sociedade ao longo da sua trajetória histórica projetou uma dicotomia entre razão e emoção, que pressupunha uma inabilidade de pensamento e emoção como seres fundantes das ações. Damásio (1996) aponta a tese de que emoção e razão estão interligadas, e que uma afeta a resposta da outra. Segundo o mesmo autor, do ponto de vista da neurociência, as emoções impactam as reações racionais. A emoção seria a representação dessa mudança transitória no estado do organismo, por meio de padrões neurais e das imagens resultantes (Damásio, 2004). Portanto, quando alguma coisa ou alguém nos atinge respondemos racional e emocionalmente. 


\section{Expressão do medo na pandemia}

Em toda a forma de sociabilidade, em todo o espaço em que há relações e interações, as emoções estão presentes, porque elas são parte dos sujeitos, do indivíduo, e o medo, sendo essa emoção natural inata, é também uma construção social. Seria a perspetiva do desenvolvimento de uma nova sociabilidade dos sujeitos neste período. Isto pressupõe a formalização de um novo pacto social que estabelece, entre outras possibilidades, uma nova relação entre o indivíduo e a sociedade mediada pelos gestores públicos.

O pressuposto é de que cabe ao gestor propor soluções que garantam a segurança e a saúde de seus cidadãos, e a estes obedecer às novas regularizações normativas propostas. $\mathrm{O}$ que de fato parece ocorrer no discurso em evidência é que não há tendência generalizante e uníssona de ações efetivas de manutenção da proteção.

Os países usando da sua autonomia agem de acordo com o que julgam mais assertivo. Os países que propuseram normas rígidas de isolamento social apresentam respostas mais efectivas ao avanço do vírus. Medidas de testagem, diagnósticos rápidos, prevenção e tratamento definidos enviam uma mensagem clara de segurança. Entretanto, a falta de definição gera insegurança.

Alguns países, entre estes o Brasil, lidam com uma postura negacionista por parte do governo central. Minimizando o risco 
e naturalizando as perdas causadas pelas mortes, falta uma direção de contenção dos efeitos nefastos do COVID-19 e das suas consequências. A geração de insegurança, dúvidas e falta de direcionamento surgem como fortes estímulos para ampliar o medo.

Ao defrontarmo-nos com o anúncio de que, vindo da China, o coronavírus se espalhava pelo mundo e com a decretação da pandemia, fomos assolados por questionamentos, dúvidas e respostas emocionais.

Como primeiro destaque a ameaça coloca em risco a vida. $\mathrm{E}$ desperta nosso medo primitivo da morte. Medo estimulado pelo ataque à nossa integridade física. Aqui, a resposta emocional é relativa ao medo natural. Quando nos sentimos ameaçados respondemos com medo. $O$ medo protege-nos e desperta três respostas: fuga, luta ou paralisação. A nossa resposta imediata ao perigo da infeção pelo coronavírus foi de fuga, pois ao protegermos os nossos lares evitámos o perigo.

Com a disseminação do contágio ocorreu também uma outra disseminação relacionada às informações geradas por toda a mídia. O excesso de informações ou suas contradições, o fenómeno das fake-news alimentou o monstro para além da sua grandeza real. A metamorfose causada pelas transformações dos espaços/tempos, formas de produzir e divulgar informações colocam-nas diante dos nossos olhos quando elas acontecem. Daí advém que acompanhar em tempo real o número de 
infetados e mortos é um estímulo emocional competente para o medo de grandes dimensões.

Em contrapartida a isso, as medidas de isolamento social, decretação de quarentena, encerramento das fronteiras entre países surtiu efeito acelerado na economia e teve impacto, sobretudo, nos trabalhadores assalariados. A perda de renda levou milhares ao redor do mundo a necessitarem de auxílios e benefícios sociais de seus governos. Intrínseco a tudo isso ficamos ancorados entre o medo natural que nos leva à proteção e à necessidade natural de subsistência, que nos obriga a enfrentar a situação e a sair, ainda que correndo o risco de contaminação.

Neste caso, a gestão central de cada país da forma como se propôs a combater ou enfrentar a pandemia e as suas consequências, é responsável pelos desdobramentos relativos à saúde física e emocional de seus cidadãos.

\section{Entre inseguranças e fragilidades sociais}

Se considerarmos que na vida em sociedade estamos sujeitos a normas legais estabelecidas e que estas orientam uma hierarquização de responsabilidades e poder, nós confrontamonos com a produção social do medo em tempos de pandemia.

Existe uma linha ténue entre medo natural e medo social. Essa diz respeito a tudo aquilo que os sujeitos, nas suas relações e sobretudo nas hierárquicas e de poder, transformam esse medo 
natural e o constroem enquanto um fenómeno social. Então o medo social é uma emoção provocada por relações de poder desequilibradas (Dias, 2007).

Como se configuram as relações de poder desequilibradas? São relações em que um indivíduo no uso do seu poder hierárquico pode beneficiar em relação ao outro, e na produção social do medo esse benefício acontece exatamente com a provocação desse medo. Aquele que está hierarquicamente superior causa o medo porque vai, consequentemente, lucrar com alguma coisa, com esse medo provocado, pois tem algo a lucrar com os indivíduos amedrontados.

Então qual é a função social do Medo? Ou a função do medo social? É a função do disciplinar, de dominar, de controlar e de manter uma ordem social estabelecida.

É conveniente expor as duas interfaces possíveis: o poder estabelecido usa o medo das consequências da pandemia para fazer com que as pessoas obedeçam às normas restritivas ou, por outro lado, como no caso do Brasil, amedronta a população exacerbando a falta de emprego, renda e condições básicas. Ao sobrepor a economia à saúde os cidadãos se sentem fragilizados, mas apesar de amedrontados impulsionados a agir².

2 No Brasil, em pleno contexto pandémico, com as orientações do Presidente da República contrárias ao isolamento e minimizando os efeitos da COVID-19, aconteceram diversas situações de exposição pública de pessoas, tanto em atos políticos, realizando manifestações e causando aglomerações, como desrespeitando o isolamento e saindo às ruas para atividades cotidianas proibidas. Este cenário é reflexo da política bolsonarista que governa o país, apesar dos esforços individuais de governadores e prefeitos no combate ao vírus. 
O medo social, é aquele medo fabricado, inculcado, construído e instalado no sujeito (Bauman, 2008). Quando ocorre a instabilidade da ordem social, o medo é utilizado como mecanismo disciplinar e leva a pessoa a sujeitar-se a determinadas ordens sociais, ainda que delas discorde. Por outro lado, existe um contraponto que também é bastante explorado nas sociedades contemporâneas, que é a utilização do medo pelo mercado como possibilidade de consumo de bens materiais e de instrumentos para proteção.

Vejamos, explora-se a violência urbana e destacamos aqui as armas, as redes de seguranças, e aí surge um novo contexto que é o contexto do medo económico, é esse medo em que essa emoção é provocada e utilizada como a exploração para a manutenção de uma determinada parcela do mercado, que é toda essa parcela que nos vende segurança. Então se provoca o medo e se vende artifícios para que você se proteja, então nós temos aí uma indústria enorme, que vende o medo, por exemplo, a indústria do armamento, e nós temos por outro lado uma indústria enorme que nos vende serviços de segurança, materiais de segurança, porteiros electrónicos e assim sucessivamente.

Em tempos pandémicos vivenciamos a corrida em busca de medicamentos que mesmo sem comprovação científica são alardeados como possível cura. Os países buscam a aquisição de Equipamentos Individuais de segurança (EPIs), respiradores entre outros e aqui instala-se a lei da oferta e da procura. 
As máscaras, propagadas como fundamentais para a segurança e proteção individual, tornou-se item acessório do vestuário, produto de primeira necessidade e acelerou um comércio que vai desde a produção doméstica à produção em larga escala. Dos modelos mais simples aos mais estilizados é uma das formas de combate ao medo.

É o medo social das ruas, os espaços públicos estão ameaçados. Então tendemos a protegermo-nos nos espaços privados de casa. E os relacionamentos e inter-relacionamentos estão intraduzíveis nesse momento. $O$ futuro ditará novas regras ou voltaremos às antigas e velhas formas de convivência. Um vírus tornou-se uma forma de sermos apresentados ao maniqueísmo entre o bem e o mal.

Toda a construção, principalmente mediática da comunicação e da informação cumpre dois papéis, informar o que é extremamente necessário ou amedrontar-nos. A polarização daquilo que é o mal ou o bem, do bandido e do mocinho, do lobo mau contra o caçador, da saúde e da doença, da vida e da morte, e assim sucessivamente. Desse modo, a exploração do maniqueísmo na sociedade também é uma construção social do medo, e age através do desenvolvimento do imaginário pessoal e coletivo.

"A perspectiva torna-se neste contexto dicotómica e maniqueísta: bons e maus em lados opostos. Como consequência desta parcialidade perceptiva, exerce-se o medo e a violência sobre os outros, para que se possa assegurar a 
ordem social. Para tal, delega-se no Estado o monopólio da violência, para melhor a controlar e limpar o mal e os maus, que são naturalmente os outros" (Dias, 2006: 301).

O medo pode manifestar-se diante de uma situação de ameaça ou perigo que nos coloca em risco. O medo líquido, segundo Bauman

“(...) não ficando no mesmo lugar, mas difuso. E o problema com o medo líquido é que, ao contrário do medo concreto e específico, que você conhece e com o qual está familiarizado, é que você não sabe de onde ele virá. (...) não há estruturas sólidas ao nosso redor nas quais possamos confiar e nas quais investir nossas esperanças e expectativas. Até mesmo os governos mais poderosos, frequentemente, não podem entregar o que prometem" (2008: 12).

Neste sentido, é necessário estabelecer práticas que considerem novas formas sociais para romper com o processo de desumanização cada vez mais crescente na nossa sociedade sob o bojo da globalização e permeada pelos princípios do neoliberalismo. É preciso entender a educação como um desafio ainda persistente na busca de possibilidades críticas e reflexivas. É importante destacar a reflexão aprofundada, que deve ser feita sobre os princípios de enfrentamento das situações aqui elencadas. 


\section{Medo social e futuro - Considerações finais}

Diante de uma realidade que se apresenta complexa e que está em curso, quais são os instrumentos para a enfrentar e as possibilidades de vivência social do medo em tempos de pandemia?

Não podemos deixar de ressaltar que a emoção do medo, seja natural ou social, nos coloca os desafios já apresentados, mas pode levar a situações mais extremas como adoecer física e emocionalmente. Constata-se assim que, se não adoecermos da COVID-19 podemos ter outros problemas.

Como forma de enfrentamento da situação e possibilitando uma vivência emocional positiva do medo destacamos alguns fatores preponderantes.

A sociedade tecnológica, da comunicação e informação digitais, possibilita a interação pessoal, ocupa o espaço das relações sociais presenciais e o mais significativo e preponderante é que nos coloca em contato direto com informações atualizadas. Conforme já destacado isso pode afetar-nos de forma negativa, pois o excesso de informação pode reforçar a produção social do medo.

Por outro lado, a informação é um caminho para o enfrentamento. "A verdade é que quanto mais esclarecidas forem as pessoas menor é a possibilidade de virem a ter medo" (Dias, 2007). 
É imperativo também argumentar-se favoravelmente sobre processos educativos, objetivando transformar as informações em conhecimento, processo de educação que se inicia e se prolonga ao longo da vida. Isto porque é preciso ensinar os métodos permitindo estabelecer as relações mútuas e as influências recíprocas entre as partes e o todo neste mundo complexo (Morin, 2000).

A Educação apresenta-se como uma perspetiva de olhar para a pandemia e para os seus desafios como possibilidade de reflexão. Neste campo encontramos apoio nas proposições da educação emocional. A disseminação dos estudos das neurociências tem dado contribuições para esta área. Processos educativos podem propiciar o conhecimento e reconhecimento da emoção do medo e possibilitar vivências emocionais positivas.

A Educação Emocional surge como relevante e pode ser entendida como um processo permanente, que se dá ao longo da vida, que potencializa o desenvolvimento emocional, como complemento indispensável ao desenvolvimento cognitivo, com a finalidade de aumentar o bem-estar pessoal e social (Bisquerra, 2000).

Isto leva-nos a refletir sobre a situação a que estamos expostos e o cotidiano, para além do fazer reativo às demandas advindas da sociedade e do poder público estabelecido. Produz ações que possibilitam o desenvolvimento das emoções, da emoção do medo e a descoberta das competências emocionais dos sujeitos. Pensar a pandemia da COVID-19 na perspetiva da emoção do 
medo é pensar na fragilidade humana. É pensar em algo que foge do controlo individual e se alicerça em verdades construídas por terceiros, na luta travada entre países desenvolvidos e países do Terceiro Mundo; entre governos centrais e periféricos de cada país, nos embates entre a ciência e a política. É pensar num contexto que, para além de uma crise de saúde pública se consolida como uma crise humanitária de perfis que estão a ser desenhados numa folha, até então em branco.

"Por sua vez, a insegurança existencial resulta da falta de confiança básica na estrutura de relações em que os indivíduos se inserem, devido aos diferentes indicadores que de forma mais ou menos inconsciente são apreendidos pelos indivíduos nos processos interaccionais" (Dias, 2006: 312).

Pode-se assim pensar que o medo é o que em primeira instância nos protege e salva e, em segunda instância, é o que nos aprisiona e aliena.

\section{Bibliografia}

Bauman, Z. (2008). Medo líquido. Rio de Janeiro: Jorge Zahar Editor.

Damásio, A. (1996). O Erro de Descartes: emoção, razão e o cérebro humano. São Paulo: Companhia das Letras.

(2004). Em busca de Espinosa. São Paulo: Companhia das Letras.

Dias, F. N. (2006). O medo enquanto emoção social: contributos para uma sociologia das emoções. Fórum Sociológico, 15/16 (II Série), pp. 295-313. 
(2007). O medo social e os vigilantes da ordem emocional. São Paulo. Instituto Piaget.

Koury, M. (2020). O Covid-19 e as emoções: pensando na e sobre a pandemia. RBSE Revista Brasileira de Sociologia da Emoção, 19, 55, abril de 2020.

Morin, E. (2000). Os Sete Saberes Necessários à Educação do Futuro. São Paulo: Cortez.

Suplemento Especial - Pensando a Pandemia à luz da Antropologia e da Sociologia das Emoções, pp. 13-26, maio de 2020 - ISSN 1676-8965. 